\title{
Diketopyrrolopyrrole (DPP)-based polytriazoles: Synthesis and Immobilization by click reaction $\dagger$
}

\author{
Periyamuthu Ramar, ${ }^{\mathrm{a}, \mathrm{b}}$ Venkatraman. Raghavendra, ${ }^{\mathrm{b}, \mathrm{c}}$ and Debasis Samanta*a,b
}

\author{
Polymer Science \& Technology division, CSIR-CLRI, Adyar, Chennai-600020, India. E-Mail: debasis@clri.res.in Fax: + 91-44-24911589; Tel: +91-44-24422059. \\ Academy of Scientific and Innovative Research, Rafi Marg, New Delhi. \\ Inorganic and Physical Chemistry Department and Centre for High Computing, CSIR-CLRI, Adyar, Chennai-600020
}

Diketopyrrolopyrrole-based polymers are generally immobilized to various surfaces for device fabrications and sensor applications. preparative methods as well as Immobilization processes play a significant role for device efficacy. In this paper, we demonstrated that while "click" polymerization can be conveniently used for the preparation of diketopyrrolopyrrole DPP-based polymer, selfassembled monolayer (SAM) formation technique is convenient for efficient Immobilization to surfaces. Computational models have been used to theoretically calculate various energy parameters. Finally, some of those surfaces have been used as reusable photocatalytic chips, in line with mechanistically similar photovoltaic chips.

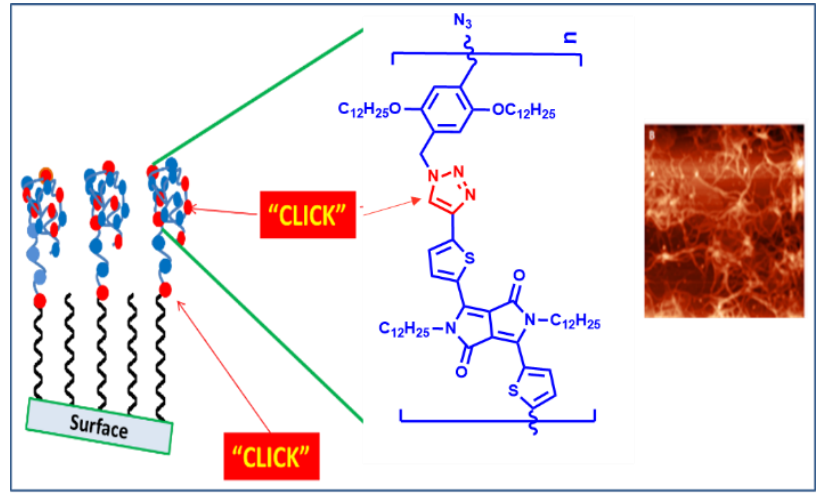

\section{INTRODUCTION}

Polymers are immobilized to various surfaces for the development of drug delivery systems ${ }^{1}$, anti-fouling surface ${ }^{2-4}$, superhydrophobic coating $^{5-9}$ to sensor devices ${ }^{10-15}$, optoelectronic devices (like Organic Light Emitting Diodes (OLED) ${ }^{16}$, Organic Fied Effect Transistors $(\mathrm{OFETs})^{17}$, and photovoltaic devices ${ }^{18,19}$ ), lithography pattern ${ }^{20}$ etc. Although drop casting or spin coating methods are frequently used for surface coatings; controlled decoration using self-assembled monolayer (SAM) formation techniques can provide more reliable and durable surfaces. In the recent review articles, we highlighted various aspects of SAM formation techniques ${ }^{21}$ particularly, SAMdriven "graft from", "graft to", "graft through" techniques. ${ }^{22}$ Each of those methodsologies have certain advantages and disadvantages. In a nutshell, while graft from method can provide a more dense Surface, graft to method offers an operational simplicity.

Formation of self-assembled onolayer (SAM) with silane molecules particularly attracted several attentions as they form covalently attached monolayer on relevant surfaces, like, silicon, indium tin oxide, glass etc. Further, the SAM formation on surfaces allows finetuning of several surface properties like wettability, conductivity etc. Such controlled decorations can facilitate enhancement of device performances, particularly in photovoltaic cells, the SAM layers with small organic molecules can tune the power conversion efficiency effectively as a electron/hole transport layers. For example, L.Yang and others demonstrated the formation of highly densed poly(3methylthiophene) self-assembled monolayer to Indium tin oxide surfaces and used as a new hole transport layer instead of PEDOT:PSS layer in bulk hetero junction polymer solar cells ${ }^{19}$. These ITO/SAM-P3MT substrates of hole transport layers provide higher power conversion efficiency, superior stability in various solvents and air and recyclability compared with ITO/PEDOT:PSS substrates. J.M.Chiu et al, fabricated the bilayer hybrid organic solar cells (ITO/SAM/ZnO/P3HT/Au) with modification of ITO electrode by SAM of n-propyltrimethoxysilanemolecules to improve the crystallinity of $\mathrm{ZnO}$ layer as well as electrical properties of device. Chiu et. al reported that the SAM modified device has improvement of the charge carrier mobility and short circuit current, for better device performances ${ }^{23}$. However, possibly only limited critical studies have been undertaken on the immobilization of specific designer polymers to surfaces using "graft to" SAM formation techniques.

Another issue related to device performance is the design of polymer-based active layers. We and other research groups reported that Diketopyrrolopyrrole, coupled with various aromatic moieties play an important role in controlling various parameters related to device performances ${ }^{24}$. While in most cases different moieties were connected with double bond or triple bond by employing Suzuki or Sonogashira coupling, several years back we reported that triazole as connector can provide interesting systems for their unique optoelectronic properties ${ }^{24}$. However, to the best of our knowledge, there is no report of employing recently developed but extremely efficient click reaction for preparing Diketopyrrolopyrrole DPP-based click polymers connected with specially designed aryl moieties via triazole linker.

In this article, we clearly demonstrated that click reaction can be conveniently used to prepare DPP-based triazole polymers or click polymers. since solubility is an important issue for the products after click polymerization, ${ }^{25}$ we introduced long alkyl chains to both monomers for improving the solubility. Further, those polymers can be covalently immobilized (graft to method) to various surfaces on pre-formed azide functionalized Self Assembled Monolayer (SAM) using alkyne end group ${ }^{26}$ of the click polymer. Computational models have been used to theoretically calculate various energy parameters. Special experimental techniques have been used for the comparative study with other immobilization methods. Finally, since photocatalytic dye degradation has a similar initiation mechanism like photovoltaic effect, we undertook detailed studies on using the material for sunlight driven dye degradation. 


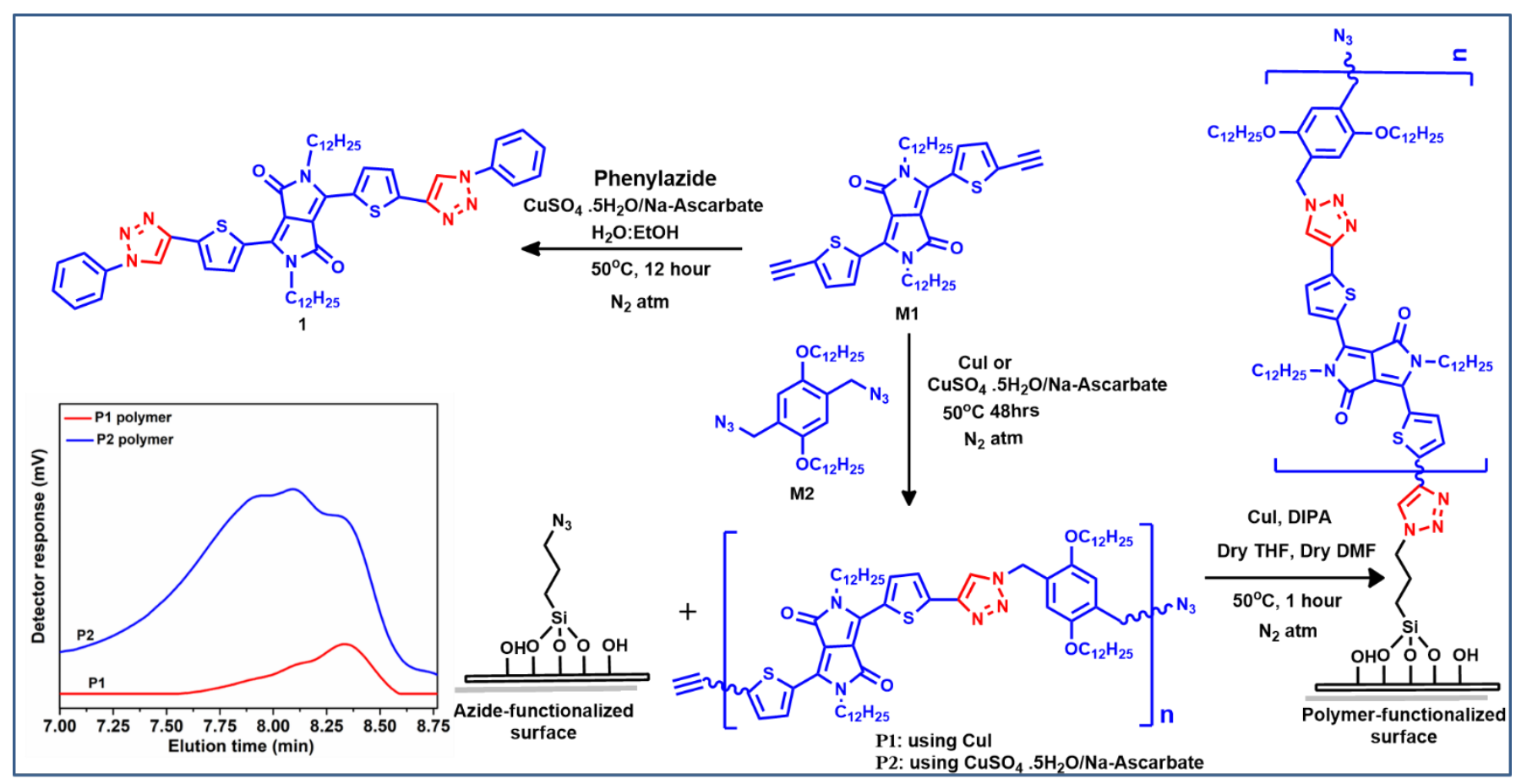

Scheme.1 "click" reaction and click polymerizations on diketopyrrolopyrrole (DPP) -based M1 monomer, followed by immobilization using self-assembled monolayer (SAM) formation technique. Insert picture: GPC chromatogram of click polymers P1 and P2.

\section{RESULTS AND DISCUSSION}

\section{1.synthesis and Optical properties of the polymers:}

Dialkynated DPP monomer (M1), diazido monomer (M2) and phenylazide (compound S7) were synthesized using modified literature procedures as described in the ESI section S2 and spectral data of that synthesized compounds were provided in ESI figure S1 to $\mathrm{S} 10^{36-38}$. Initially we attempted the model click reaction of dialkynated DPP monomer (M1) by reacting with phenyazide in $\mathrm{THF}$ - water mixture at $50^{\circ} \mathrm{C}$ in the presence of $\mathrm{CuSO}_{4} .5 \mathrm{H}_{2} \mathrm{O}$ and Naascarbate shown in reaction scheme.1. After 22 hours the product (compound 1) was recovered and purified by column chromatography and characterized by FT-IR and ${ }^{1} \mathrm{H}$ NMR spectroscopy techniques. In FT-IR spectrum; after click reaction the disappearance of azide peak was observed at $2100 \mathrm{~cm}^{-1}$ and in ${ }^{1} \mathrm{H}$ NMR spectrum the new characteristic appeared at $7.8 \mathrm{ppm}$ for triazole ring $\mathrm{C}-\mathrm{H}$ proton which reflected the success of the click reaction on monomer 1 molecule (shown in figure S10 in ESI) ${ }^{39}$.

After establishing the condition for click reaction on model substrate, click polymerization reaction were performed using two different catalyst systems (CuIf or P1 polymer and $\mathrm{CuSO}_{4} .5 \mathrm{H}_{2} \mathrm{O} / \mathrm{Na}-$ ascarbate for $\mathrm{P} 2$ polymer) separately maintaining reaction condition at $50^{\circ} \mathrm{C}$ for 48 hours in presence of base ${ }^{24,40}$. In both the cases, after completion of polymerization, the characteristic color change from red to dark violet was observed. The crude product was purified by extraction with different solvents sequentially, like methanol, acetone, diethyl ether and chloroform. Finally we obtained the click polymers in chloroform fraction. The elaborated synthetic procedure is given in the experimental part. The formation of click polymers in both cases were confirmed by FTIR, NMR and GPC. As observed by FT-IR spectroscopy in figure $1 \mathrm{~A}$, near complete disappearance of peaks at around $2100 \mathrm{~cm}^{-1}$ corresponding to azide and alkyne group stretching indicated the success of click polymerization . A small residual peak at $2100 \mathrm{~cm}^{-1}$ indicated the presence of alkyne / azide end groups in the polymer chains. ${ }^{40}$

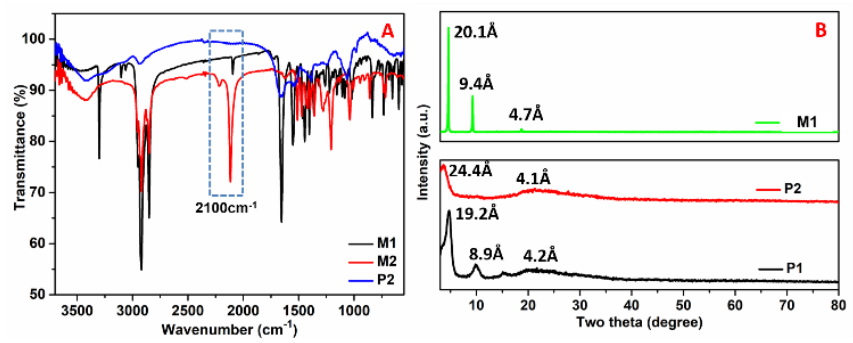

Figure 1. (A) FT-IR and (B) XRD patternsof monomers and click polymers (P1 and P2)

Further the formation of polymers were confirmed by ${ }^{1} \mathrm{H}$ NMR spectroscopy (S11 in ESI and Figure 2). In ${ }^{1} \mathrm{H}$ NMR spectrum, the new peak at 7.63-7.85 ppm confirmed the formation of triazole ring and disappearance of the peak indicated near completion of reaction. Two C-H protons signals of thiophene rings were observed at $8.90-9.15 \mathrm{ppm}$ and at 7.65-7.25 ppm as a broad signal. All other characteristic aliphatic $\mathrm{CH}_{2}$ and $\mathrm{CH}_{3}$ proton signals were also observed. As observed from GPC, the Mn values of polymers are 7435 and 5967 respectively for P1 and P2, indicating different degree of polymerization while using $\mathrm{CuI}$ catalyst. 


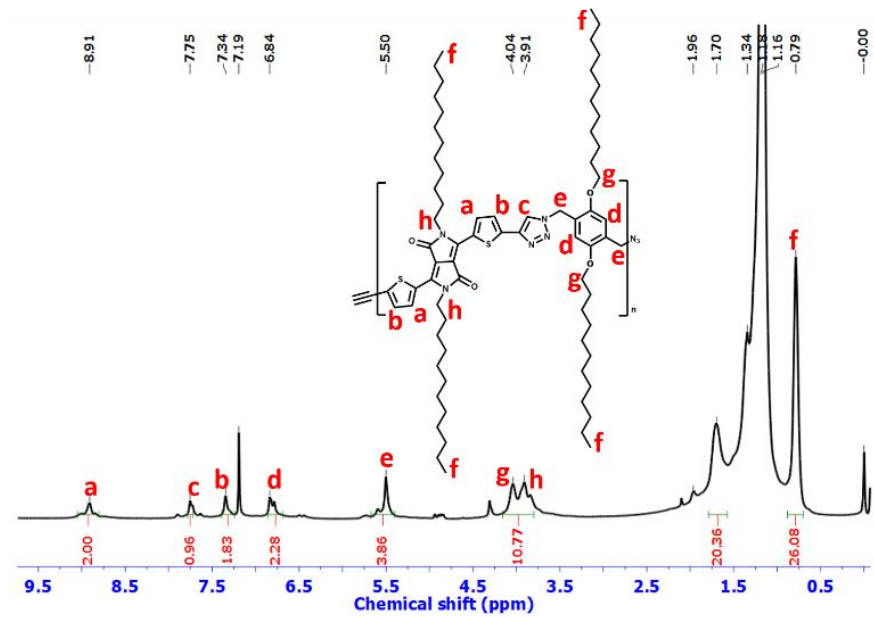

Figure2. ${ }^{1} \mathrm{H}$ NMR spectrum of click polymer P2

The absorption and emission spectral analysis of polymers were taken in $\mathrm{CHCl} 3$ solution as shown in figure 3. Dialkynated DPP monomer showed maximum absorption wavelength at $586 \mathrm{~nm}$, which is attributed to $\pi-\pi^{*}$ electronic transition of diketopyrrolopyrrole units ${ }^{39}$. After polymerization, similar types of absorption were observed indicating the in difference in extension of conjugation during polymerization. In fluorescence spectra the maximum emission wavelength of DPP monomer was shown at 602 $\mathrm{nm}$ and click polymers was shown at $612 \mathrm{~nm}$ revealing a good fluorescence activity ${ }^{39}$. The geometry, electronic structure and frontier orbital energy levels (FMOs) (HOMO and LUMO) of click polymer molecule with one repeating unit were studied by using density functional theory calculations. We calculated the energy level values of ground (LUMO) and exited state (HOMO) with respect to the click polymer electronic structure as $-2.52 \mathrm{eV}$ and $4.81 \mathrm{eV}$ respectively with theoretical bandgap values of $2.29 \mathrm{eV}$ (figure 3(B)). This results reveal that, the theoretical bandgap values have provide good agreement with experimental values. Further, it was observed from computational models that both HOMO and LUMO were located in the diketopyrrolopyrrole (DPP) moiety and it can be facilitate the intermolecular charge transfer transition between DPP and quionol units of click polymer ${ }^{41,42}$.
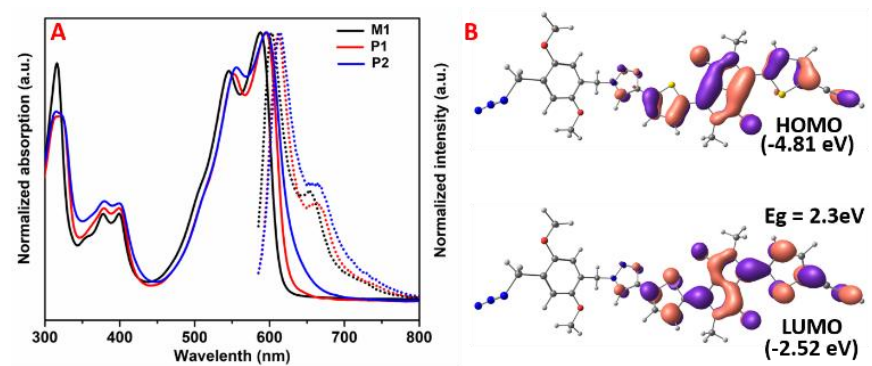

Figure 3.(A) combined UV-Vis absorption and emission spectra of M1 monomer and polymers (P1 and $\mathrm{P} 2)$ in solution $(\mathrm{CHCl3})$ (B) Topologies of frontier molecular orbital diagram of analogue of click polymer structure with one repeating unit

Thermal analysis of monomer and polymers were studied by TGA and DSC measurements with heating rate at $10^{\circ}$ per minutes (figure 4A, 4B and ESI figure S6). The TGA data shows the dpp monomer has more stability upto $391{ }^{\circ} \mathrm{C}$ plausibly due to the $\pi-\pi$ stacking between the dpp molecules. The onset decomposition temperature of click polymer $\mathrm{P} 1$ and $\mathrm{P} 2$ has $169^{\circ} \mathrm{C}$ and $175^{\circ} \mathrm{C}$ respectively, plausibly due to the slow breaking of alkyl chains from polymers. The glass transition temperature of polymers wereanalyzed by DSC instrument and the tg value of click polymer was found to be at around $55^{\circ} \mathrm{C}-60^{\circ} \mathrm{C}$. The relatively low values of glass transition temperature can be attributed to the presence of more alkyl chains and more flexibility between the polymer chains ${ }^{43}$.
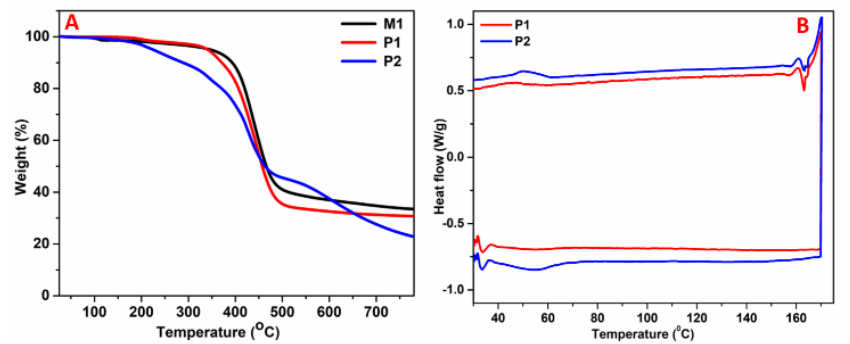

Figure 4. Thermal analysis data of monomer and click polymers (P1 and P2) (A)TGA and (B) DSC

The crystalline nature of monomer and polymers was studied by powder XRD at two theta ranges of 3-80 degree as shown in figure 1. The DADPP monomers showed three different sharp peaks at $4.60,9.28$, and 18.69 degrees at two theta values ${ }^{44}$. The corresponding $\mathrm{d}$ spacing values, mentioned in figure $1 \mathrm{~B}$, indicated the dpp monomer (M1) is highly crystalline in nature. The click polymer P2 showed two broad XRD patterns with two theta values at 3.83 and 21.30 degrees. It was indicating the highly amorphous nature and the two planes of diffraction in the polymer microstructures due to the presence of $\pi-\pi$ stacking in between dpp cores. The P1 polymer shows four peaks at 4.71, 9.80, 15.11, and 20.73 degrees of two theta values.

\subsection{Preparation and characterization of click polymer functionalized surfaces by "graft to" method}

Since the above-mentioned polymer has alkyne as an end functional group, it can be directly clicked to azide functionalized surfaces unlike the strategy used by other research groups where end alkyne groups have been incorporated separately ${ }^{45}$. For surface functionalization, we first synthesized 3-azido propyl trimethoxy silane from 3-chloropropyltrimethoxy silane in optimum condition following previous literature procedure (ESI reaction scheme S6 and figure S13). Next, the glass surfaces $(2 \mathrm{~cm} \times 2 \mathrm{~cm}$ square slides $)$ were treated with piranha solution at $90^{\circ} \mathrm{C}$ for 1 hour for making the free hydroxyl groups on surfaces. For formation of azide functionalized glass surfaces (SAM surface), the hydroxylated surfaces were reacted with 3-azidopropyltrimethoxysilane in toluene medium at $100^{\circ} \mathrm{C}$ for 2 hours. After the completion of reaction, the slides were washed with toluene and methanol. Azide functionalized SAM were characterized by ATR-IR spectroscopy where the characteristic peaks were observed at $2095 \mathrm{~cm}^{-1}$ and $2870 \mathrm{~cm}^{-1}$ corresponding to the $\mathrm{N}_{3}$ and aliphatic $\mathrm{CH}_{2}$ stretching frequency respectively. Graft to click reaction on azide-functionalized surface was successfully carried out by copper baed catalyst, as described in experimental section ${ }^{24,45}$. It was initially confirmed by FT-IR and XPS analysis as shown in figure 5A and 5B. In ATR-IR the disappearance of azide characteristic peak at $2095 \mathrm{~cm}^{-1}$ and appearance of new polymer characteristic peaks at $1654 \mathrm{~cm}^{-1}$ $2850 \mathrm{~cm}^{-1}$ and $2925 \mathrm{~cm}^{-1}$ was observed. 
The success of "graft to" click reaction on polymer-functionalized surface was further confirmed by XPS analysis, the survey scan spectrum of "graft to" surface was shown in figure 5B. In the XPS analysis of azide-functionalized SAM surfaces, two kind of nitrogen signals at 400 and $410 \mathrm{eV}$ binding energy corresponding to the two different charges of $\mathrm{N}(1 \mathrm{~s})$ atoms ws observed while after polymer functionalization, only one peak at $398.8 \mathrm{eV}(4.09 \%)$ attributed to the triazole nitrogen atoms were observed in line with earlier reports in literature ${ }^{24}$. Other characteristic elements like $\mathrm{C}(1 \mathrm{~s}), \mathrm{Si}(2 \mathrm{p}), \mathrm{S}(2 \mathrm{p})$, and $\mathrm{O}(1 \mathrm{~s})$ peaks were present at 284.2 (39.60\%), $102.8(19.44 \%)$, $163.1(0.09 \%)$ and $532.4 \mathrm{eV}(31.19 \%)$ respectively.
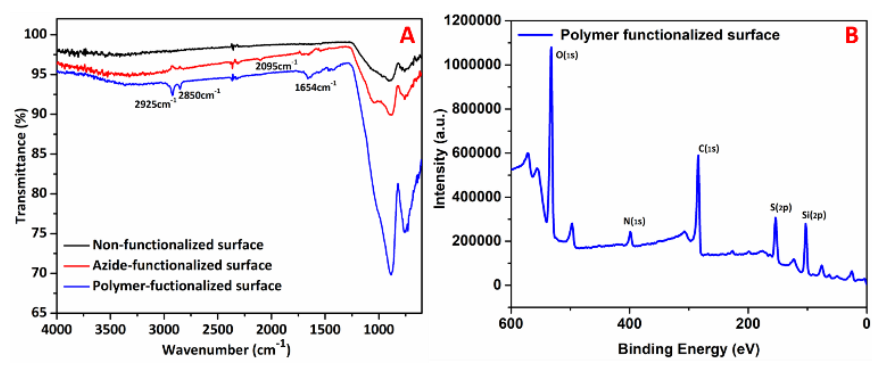

Figure 5. (A) ATR-IR spectra of non-functionalized surface, azidefunctionalized surfaceand polymer-functionalized surface. (B) XPS spectrum of polymer functionalized surface.

\subsection{Surface property characterization of azide-functionalized surface (SAM) and polymer-functionalized surfaces}

The surface property and surface morphology was studied by water contact angle measurement, scanning electron microscopy, fluorescence microscopy, ellipsometry, and atomic force microscopy. As observed from ellipsometry, the thickness of polymer-functionalized surface and drop-casted surfaces were $90 \mathrm{~nm}$ and $110 \mathrm{~nm}$ respectively, which is more than generally observed thickness of azide-functionalized surface $(\mathrm{SAM})^{24}$. Ellipsometric thickness measurements at different places revealed the formation of dense polymer brushes for polymer-functionalized surface ("graft to" method). The contact angle measurement data revealed that the dropcasted surface $\left(115 \pm 1^{\circ}\right)$ has more contact angle value than polymerfunctionalized surfaces $\left(90 \pm 1^{\circ}\right)$, which may be attributed to more roughness of the surface (figure 6). As a control, blank surface showed the contact angle value of $30 \pm 1^{\circ}$ due to presence of more hydroxyl groups and high smoothness. When 3azidopropyltrimethoxy silane group has been introduced on the surface by SAM formation, the hydrophobicity was increases slightly upto57 $\pm 1^{\circ}$ (SAM glass surafce), attributed to the anchoring of azido alkyl chains on the surfaces.

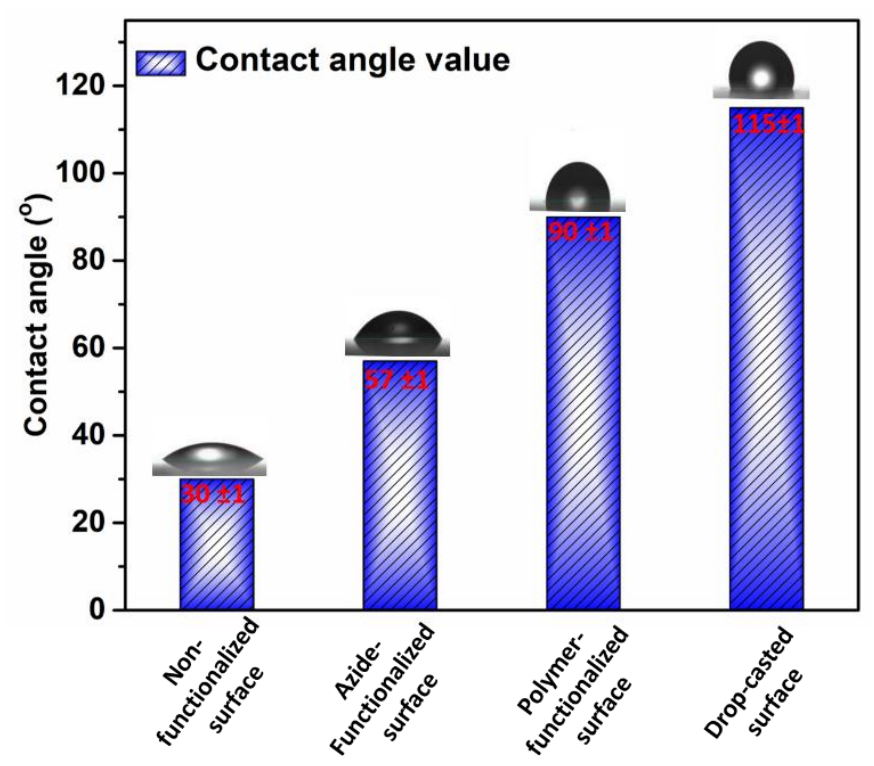

Figure 6. Contact angle values of surfaces before and and after functionalizzation

As we mentioned above, the click polymers has fluorescent property (emission wavelength is $612 \mathrm{~nm}$ in visible region), so we have checked the fluorescent nature of surfaces (after and before grafting) by fluorescence microscopy in $40 \mathrm{X}$ magnifications with excitation at $550 \mathrm{~nm}$ (showed in figure 8.). The fluorescence microscopic images revealed that blank and azide-functionalized glass surfaces did not emit any fluorescent color at $550 \mathrm{~nm}$ excitation. The polymer immobilized surfaces ("graft to" and drop casted) showed strong red emission. But in polymer-functionalized ("graft to" method) surfaces, emission occurs more evenly compared than drop-casted surfaces presumably due to more orderly nature (Figure $7 \mathrm{c}$ and $7 \mathrm{~d}$ )
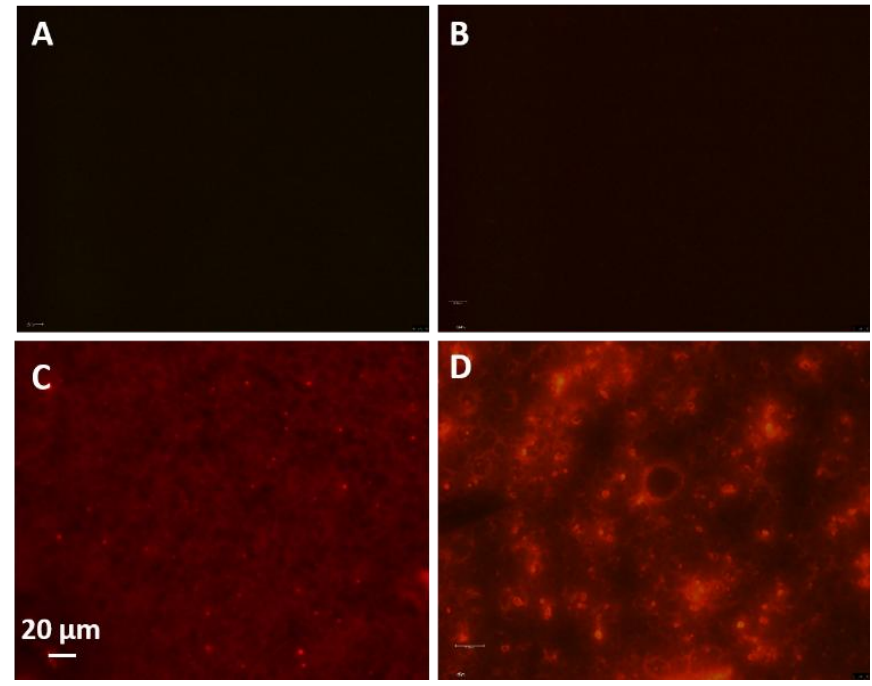

Figure 7. fluorescence microscope images of (A) unfunctionalized surface, (B) azide-functionalized surface, C) polymer-functionalized surface (graft to method) and (D) polymer drop-casted on surface. All images were taken under same magnifications.

The surface morphology and roughness profile analysis of polymer thin films was studied by HRSEM and AFM instruments. From the HRSEM microscopic pictures of surfaces, (Figure 8) we observed 
the graft to method provided smoother surfaces compared to dropcasted surfaces. This was also corroborated by AFM analysis. The AFM topographic images of azide-functionalized surface (SAM), polymer-functionalized surface and drop-casted surfaces were presented in Figure 9. For azide-functionalized (SAM) surface, a non- feature morphology with smoother surface (RMS roughness is $2.98 \mathrm{~nm}$ ) was observed. On the other hand, the polymer drop-casted surfaces exhibited the crosslinked fibrillar ribbon structures with aggregated form (surface roughness is $12.95 \mathrm{~nm}$ ), plausibly due to the tendency of DPP click polymer to forming the self-assembldd structures when drop casted on surfaces as reported by xi et al, showing fibrillar ribbon morphology. ${ }^{46}$ The polymer-functionalized surfaces also were showed the clear dispersed fibrillar morphology with more features (surface roughness is $8.43 \mathrm{~nm}$ ), possibly due to the self assembly of the dpp polymer backbone chains through $\pi-\pi$ stacking interaction in 'Graft to' functionalization.

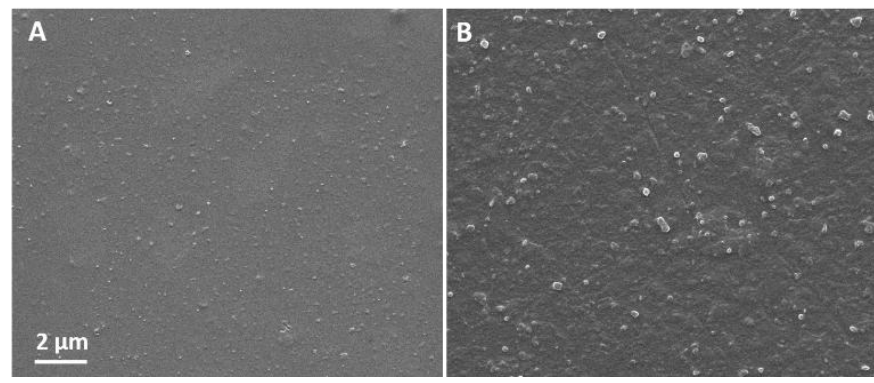

Figure 8. High resolution SEM images of (A) polymer-functionalized surface (graft to method) and (B) polymer drop-casted on surface.
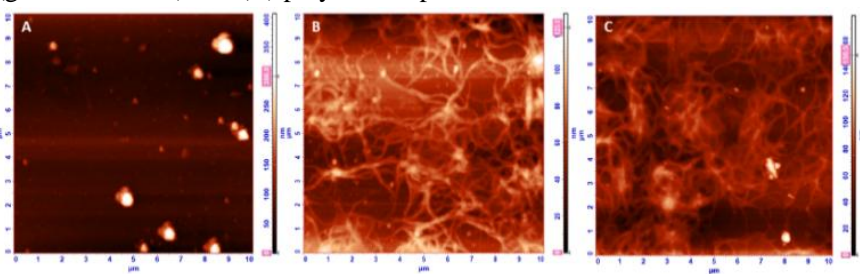

Figure 9. Atomic force microscope topography images of (A) azidefunctionalized surface, (B) polymer-functionalized surface (graft to method) and (C) polymer drop-casted on surface.

\subsection{Preparation and characterization of $\mathrm{ZnO}$ and click polymer} sensitized $\mathrm{ZnO}$ photocatalyst

Synthesis of $\mathrm{ZnO}$ particles from zinc acetate dihydrate and sodium hydroxide were performed under optimum condition and the solid particles were dried at $120^{\circ} \mathrm{C}$ for 24 hours under vacuum ${ }^{47}$. The polymer sensitization of $\mathrm{ZnO}$ semiconductors was performed by making the composites of $\mathrm{ZnO}$ with $1 \mathrm{w} \%$ of polymer (P2). Briefly, in a $100 \mathrm{~mL}$ single neck round bottom flask, $500 \mathrm{mg}$ of $\mathrm{ZnO}$ was dispersed in $50 \mathrm{~mL}$ of ethanol with sonication. Simultaneously prepared the polymer $(5 \mathrm{mg})$ solution in $5 \mathrm{~mL}$ of tetrahydrofuran The polymer solution was added dropwise into $\mathrm{ZnO}$ dispersion followed by 2 hours stirring vigorously. The solvents were evaporated and finally bluish white solid was obtained after drying. (480 mg).

The pristine $\mathrm{ZnO}$ and polymer sensitized $\mathrm{ZnO}$ catalysts (polymer$\mathrm{ZnO}$ ) were characterized by FT-IR, UV-Vis DRS, UV-fluorescence, $\mathrm{XRD}$, and SEM analysis (provided in ESI). The formation of $\mathrm{ZnO}$ was confirmed by FT-IR spectrum (see in ESI figure S14) and it has characteristic peaks at $430 \mathrm{~cm}^{-1}$ attributed to the $\mathrm{Zn}-\mathrm{O}$ bond stretching frequency. In the case of polymer- $\mathrm{ZnO}$, the peaks were observed at $1750 \mathrm{~cm}^{-1}$ and at $2950-3010 \mathrm{~cm}^{-1}$ corresponds to the amide $\mathrm{C}=\mathrm{O}$ bond and $\mathrm{C}-\mathrm{H}$ bond (aromatic and aliphatic) stretching frequency of click polymer. From solid state UV DRS spectroscopy (see in ESI figure S15 A and S15 B) we obtained the bandgap value of pristine $\mathrm{ZnO}$ and click polymer (P2) at $3.10 \mathrm{eV}$ and $1.55 \mathrm{eV}$ respectively which belongs to their onset absorption wavelength. After polymer incorporation, the bandgap energy did not change significantly due to the non covalent interaction between polymers and $\mathrm{ZnO}$. In the composite of polymer and $\mathrm{ZnO}$, broadening of absorption band (around at $400-800 \mathrm{~nm}$ ) was observed. The photoluminescence spectra of $\mathrm{ZnO}$ and $\mathrm{P} 2-\mathrm{ZnO}$ was obtained from ethanol with excitation wavelength of $350 \mathrm{~nm}$. In the case of $\mathrm{ZnO}$ (ESI fig. S16), four bands in the range of 380, 408, 431 and $453 \mathrm{~nm}$ were noticed. The emission band at $380 \mathrm{~nm}$ may be attributed to near-band-edge (NBE) emission of $\mathrm{ZnO}$, which was slightly shifted to $384 \mathrm{~nm}$ in the composites. Slight shifting of other emission bands were also observed in the nanocomposites However, increases in the fluorescence intensity from $\mathrm{P} 1-\mathrm{ZnO}$ to $\mathrm{P} 2-\mathrm{ZnO}$ (compared with $\mathrm{ZnO}$ bands) is high possibly because of the electron transfer between polymer and $\mathrm{ZnO}$. XRD were performed for $\mathrm{ZnO}$ and the composites to study the crystallinity (S17)). For $\mathrm{ZnO}, 2 \theta$ values were obtained as several sharp peaks in the range of $31-76$ degree in line with reported values to indicate good amonts of crystalinity. The crystallite size of $\mathrm{ZnO}$ is $37.61 \mathrm{~nm}$ and for $\mathrm{P} 2-\mathrm{ZnO}$ is $28.84 \mathrm{~nm}$, indicating that after polymer incorporation with $\mathrm{ZnO}$, indicated physical adsorption, leading to decrease in size. So it can help to increase the surface area as well as photocatalytic efficiency. In P2$\mathrm{ZnO}$ XRD pattern, a broad peak of at 15 to 35 degree can be attributed to the presence of polymer.. Further, dynamic light scattering (DLS) was used to analyze the sizes of particles (Figure $\mathrm{S} 18$ in ESI) showed sizes of $\mathrm{ZnO}$ and $\mathrm{P} 2-\mathrm{ZnO}$ particles were in the ranges of $473.8 \mathrm{~nm}$ and 472.5 respectively. The surface morphology was studied by scanning electron microscopy (SEM), (ESI Page S11, Figure S19) to show that the $\mathrm{ZnO}$ particles have irregular shape morphology due to more agglomeration. In the case of P2$\mathrm{ZnO}$,images showed the presence of a polymer matrix that can prevent agglomeration.

\subsection{Photocatalytic dye degradation study evoluation}

Photocatalytic dye degradation studies were undertaken separately using click polymers synthesized in solution, as well as the polymer functionalized surfaces, particularly for comparison. First to evaluate the photocatalytic efficiency, we prepared the composite catalysts $(\mathrm{P} 2-\mathrm{ZnO})$ from $\mathrm{ZnO}$ and click polymer (P2). For making thin film catalysts, either $\mathrm{ZnO}$ was drop casted on polymer functionalized surfaces (abbreviated as 'Graft to' $\mathrm{ZnO}$ ), or already prepared $\mathrm{P} 2-\mathrm{ZnO}$ nanocomposites was dropcasted on glass surface (abbreviated as P2$\mathrm{ZnO}$ film). $\mathrm{ZnO}$ alone was also drop casted separately to make $\mathrm{ZnO}$ film. For comparison and better understanding of photocatalysis under different conditions, we performed the photocatalytic degradation of dyes like RhodaminB (RhB) or Methylene blue (MB) by different catalysts like $\mathrm{ZnO}$ powder, $\mathrm{P} 2-\mathrm{ZnO}$ powder, $\mathrm{ZnO}$ film, $\mathrm{P} 2-\mathrm{ZnO}$ film and graft to $\mathrm{P} 2-\mathrm{ZnO}$ films under natural sunlight. Different experimental conditions were used to understand (i) effect of initial concentration of dye, and (ii) effect of irradiation time. The detailed experimental set up for dye degradation procedure was described in $\mathrm{ESI}^{47}$.

In the composites of diketopyrrolopyrrole conjugated polymers with $\mathrm{ZnO}(\mathrm{P} 2-\mathrm{ZnO})$, the polymer can be strongly binded on the $\mathrm{ZnO}$ surfaces due to having the different hetero atoms (like $\mathrm{S}, \mathrm{N}$, and $\mathrm{O}$ ) 
in polymer backbones. Since, the click polymer have moderately low band gap $(1.7 \mathrm{eV})$ with broad range of absorption $(450-800 \mathrm{~nm})$, it can facilitate to act as a photosensitizer for $\mathrm{ZnO}$ with wide band gaps. On the other hand, for preparing the film photocatalysts, we obtained photosensitizer film by drop casting the very thin layer of $\mathrm{ZnO}$ particles on polymer functionalized surfaces ('Graft'- $\mathrm{ZnO}$ film). This was done by keeping in mind that the possible mechanism of photocatalytic degradation involving first with the polymer molecules absorbing the more amount of photons (because of broad range of absorption) as well as $\mathrm{ZnO}$ also absorbing less number of photons to excite the electrons forming holes in HOMO levels and and accumulating electrons in LUMO levels. The high electron transfer property of polymers can facilitate the transfer of electrons (in LUMO of polymer) to LUMO of $\mathrm{ZnO}$. Then the electrons and holes can react with $\mathrm{O}_{2}$ and $\mathrm{H}_{2} \mathrm{O}$ respectively in dye solution to form $\mathrm{O}_{2}{ }^{-}$and $\mathrm{OH} \cdot$ radicals. These active radical species can be used to degrade the dye molecules.

2.5.1. Photocatalytic degradation of $\mathrm{RhB}$ and MB dyes using $\mathrm{ZnO}$ powder, P2-ZnO powder, $\mathrm{ZnO}$ films and $\mathrm{P} 2-\mathrm{ZnO}$ films under sunlight irradiation

\subsection{1(a).Photocatalytic evaluation of RhB dye}

Figure 10(A) shows the effect of concentration of dye content on dye degradation. Interestingly, $\mathrm{ZnO}$ catalyst $(20 \mathrm{mg}$ ) offered around $25 \%$ dye removal in $12 \mathrm{ppm}$ concentration but while in the case of P2$\mathrm{ZnO}$ composites, effective dye degradation was $77 \%$ in same condition, indicating that the photosensitization occurs when the light was irradiated on the composites system during the photocatalytic dye degradation. On the other hand, the filmphotocatalysts showed high catalytic efficiency for $\mathrm{ZnO}$ film at $43 \%$ and for $\mathrm{P} 2-\mathrm{ZnO}$ film at around $88 \%$ compared to their powder form catalysts, which may be attributed to increasing the surface area of catalysts covered by dye solution while making films.
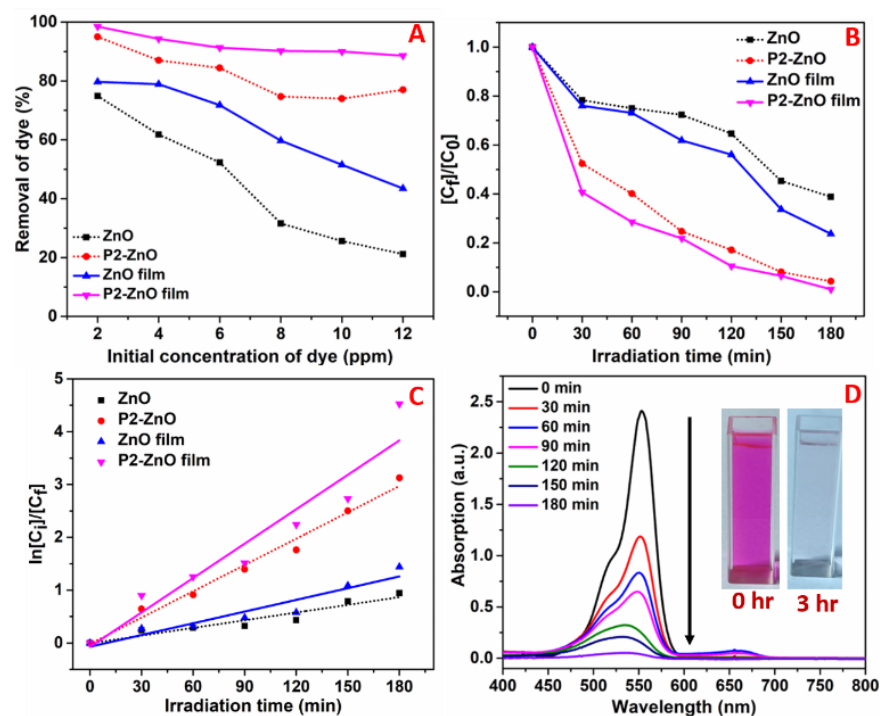

Figure 10. Photocatalytic degradation of Rhodamine $B(R h B)$ dye using $\mathrm{ZnO}, \mathrm{P} 2-\mathrm{ZnO}$ composite, $\mathrm{ZnO}$ film ( $\mathrm{ZnO}$ coated on surface) and $\mathrm{P} 2-\mathrm{ZnO}$ film (composite coated on surface) separately. (A) plot showing the effect of initial concentration, (B) plot showing effect of irradiation time, (C) Kinetic study plot and (D) UV-Vis spectrum of solution after irradiatiating for different time intervals using $\mathrm{P} 2-\mathrm{ZnO}$ film catalyst (in set picture : pictorial images of dye solution before and after $3 \mathrm{hr}$ of irradiation)
To calculate the rate of the reaction of photocatalytic degradation, we have performed the photocatalysis in different time intervals of irradiation. The efficiency was achieved by using P2-ZnO film at around $99 \%$ dye removal in $180 \mathrm{~min}$ (shown in figure.10(B)). We obtained the rate constant values at $0.004 \mathrm{~min}^{-1}, 0.016 \mathrm{~min}^{-1}, 0.007$ $\mathrm{min}^{-1}$ and $0.021 \mathrm{~min}^{-1}$ for $\mathrm{ZnO}, \mathrm{P} 2-\mathrm{ZnO}, \mathrm{ZnO}$ film, $\mathrm{P} 2-\mathrm{ZnO}$ film catalysts respectively. These results reveal that, the rate of the reaction values with $\mathrm{P} 2-\mathrm{ZnO}$ film catalyst was increased five times compared to bare $\mathrm{ZnO}$ catalyst indicating that the diketopyrrolopyrrole conjugated polymer plays an important role in photocatalysis (figure. 10(C)). The UV Vis spectra of solution shows the gradual decrease in the absorption values during different time of irradiation (figure.10 (D)). The pictorial images of dye solution (after and before irradiation) also indicates the near complete degradation in 3 hours.

\subsection{1(b).Study on photocatalytic degradation of MB dye}

Further, we studied the photocatalytic activity of prepared $\mathrm{P} 2-\mathrm{ZnO}$ composites by studying the degradation of methylene blue dye under natural sunlight by varrying the initial concentration of dye solution (5ppm, 10ppm, 15ppm, 20ppm, 25ppm and 30ppm) and effect of irradiation time ( $0 \mathrm{~min}, 30 \mathrm{~min}, 60 \mathrm{~min}, 90 \mathrm{~min}, 120 \mathrm{~min} 150 \mathrm{~min}$ and $180 \mathrm{~min}$ ). Figure 11 (A) shows the plot between removal of dye and initial concentration of $\mathrm{MB}$ dye with powder and film photocatalyst of bare $\mathrm{ZnO}$ and $\mathrm{P} 2-\mathrm{ZnO}$ composite. These results showed that the percentage of dye removal was gradually decreased by increasing the initial dye concentration, and the $\mathrm{P} 2-\mathrm{ZnO}$ composites provide high catalytic efficiency compared to pristine $\mathrm{ZnO}$. In this case also, the $\mathrm{ZnO}$ film photocatalyst showed to enhance the degradation ability (63.9\%) compared with $\mathrm{ZnO}$ powder $(51.1 \%)$, because of more surface area Thus, the $\mathrm{P} 2-\mathrm{ZnO}$ film catalyst can degrade the maximum amount of dye molecules of around $92.4 \%$ within 2 hours irradiation in $30 \mathrm{ppm}$ of dye concentration which was higher than the both pristine $\mathrm{ZnO}$ film (63.9\%) and $\mathrm{P} 2-\mathrm{ZnO}$ (77.6\%) composite catalysts due to the enhanced photosentizing property by conjugated polymer (P2) to the $\mathrm{ZnO}$ nanoparticles and film formation with high surface area of $\mathrm{ZnO}$.
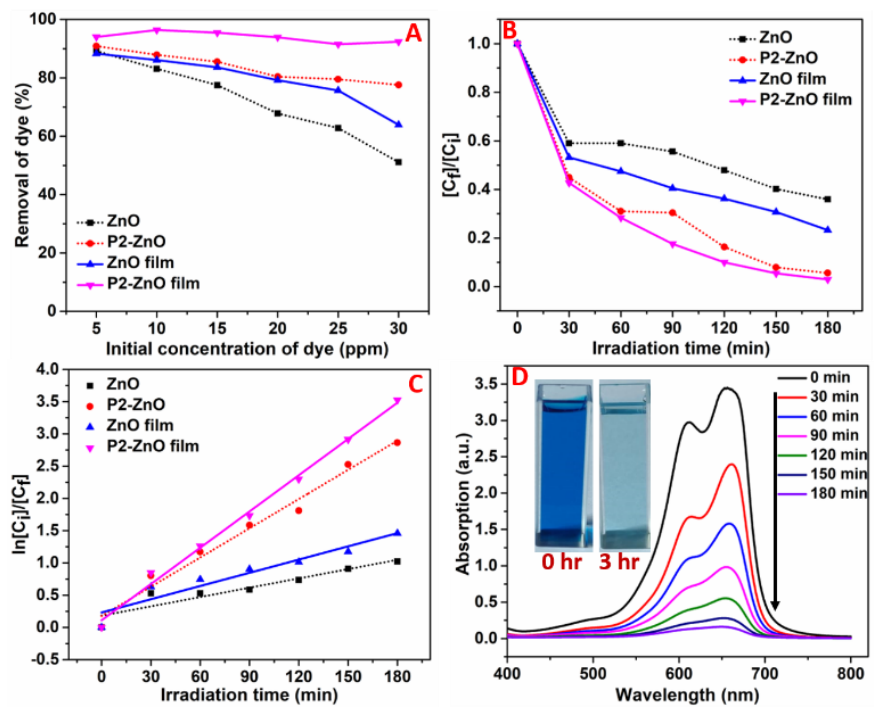

Figure 11. Photocatalytic degradation study of Methylene Blue (MB) dye using $\mathrm{ZnO}, \mathrm{P} 2-\mathrm{ZnO}$ composite,, $\mathrm{ZnO}$ film ( $\mathrm{ZnO}$ coated on surface) and $\mathrm{P} 2-$ $\mathrm{ZnO}$ film (composite coated on surface) separately. (A) Effect of initial 
concentration, (B) Effect of irradiation time, (C) kinetic study plot and (D) $\mathrm{UV}-\mathrm{Vis}$ spectral data of solution after irradiating at different time interval using P2-ZnO film catalyst (in set picture : pictorial images of dye solution before and after $3 \mathrm{hr}$ irradiation)

Figure 11 (B) described the catalytic activity of those catalysts in effect of irradiation time from $0 \mathrm{~min}$ to $180 \mathrm{~min}$. Here, we can see the dye removal in terms of $\mathrm{C}_{\mathrm{f}} / \mathrm{C}_{\mathrm{i}}$ values was decreased gradually by increasing the irradiation time and the $\mathrm{P} 2-\mathrm{ZnO}$ film catalyst provide better catalytic efficiency of around $97 \%$ after 180 minutes of sunlight irradiation in $30 \mathrm{ppm}$ initial $\mathrm{MB}$ dye concentration, which was higher than the other unmodified catalysts (64\% for pristine $\mathrm{ZnO}, 94.3 \%$ for $\mathrm{P} 2-\mathrm{ZnO}$ and $76.7 \%$ for $\mathrm{ZnO}$ film). We have studied the rate of the degradation during $\mathrm{MB}$ dye degradation by analysing the kinetic plot which indicated a pseudo first order reaction with respect to the different irradiation time. We obtained the rate of the reaction as $0.018 \mathrm{~min}^{-1}$ for $\mathrm{MB}$ dye degradation with $\mathrm{P} 2-\mathrm{ZnO}$ film and it was 3 fold higher than the bare $\mathrm{ZnO}\left(0.004 \mathrm{~min}^{-1}\right)$ and other catalysts $\left(0.006 \mathrm{~min}^{-1}\right.$ for $\mathrm{ZnO}$ film and $0.018 \mathrm{~min}^{-1}$ for $\mathrm{P} 2-\mathrm{ZnO}$ film) (the fitted curves of kinetic plot in figure $11(\mathrm{C})$ ). Figure 11(D) showed the UV Vis spectral data of methylene blue dye after light irradiation with different time intervals in presence of $\mathrm{P} 2-\mathrm{ZnO}$ film photocatalyst and we observed the absorption values decreased gradually from 0 minutes to 180 minutes. As noted from Figure 11.D (inset picture) of the photograph images of MB dye solutions (before and after light irradiation)visually the decoloration of dye solution was observed.

The above photocatalytic dye degradation ( $\mathrm{RhB}$ and $\mathrm{MB}$ dyes) experiment results reveal that the conjugated click polymercomposite has acted as a good photosensitizer macromolecule with $\mathrm{ZnO}$ nanoparticles and it can enhance the catalytic ability by making the complete degradation of organic dyes $(\mathrm{RhB}$ and $\mathrm{MB})$ within 3 hours as a film photocatalyst.

2.5.3. Photocatalytic evaluation of $\mathrm{ZnO}$ films ( $\mathrm{ZnO}$ coated on surface) and "Graft to" ZnO film [ZnO-coated on polymerfunctionalized (graft to method) surface]

The influence of the "Graft to" surfaces on photocatalytic degradation of $\mathrm{RhB}$ dye with $\mathrm{ZnO}$ nanoparticles were studied systematically by varying the $\mathrm{ZnO}$ contents and simultaneously comparing with controlled $\mathrm{ZnO}$ films (shown in Figure 12). First we prepared the $\mathrm{ZnO}$ and 'Graft to' $\mathrm{ZnO}$ films by drop casting the $\mathrm{ZnO}$ nanoparticles with different amount $(1 \mathrm{mg}, 2 \mathrm{mg}, 3 \mathrm{mg}, 4 \mathrm{mg}, 5 \mathrm{mg}$, and $6 \mathrm{mg}$ ) on glass and polymer-functionalized surfaces respectively. Then the $\mathrm{ZnO}$ films and 'Graft to' $\mathrm{ZnO}$ film surfaces were used as a film photocatalyst in photocatalytic degradation of RhB dye with 10 ppm initial concentration under 2 hours sunlight irradiation. Figure 12(A) plot showed the removal of dye in terms of percentage after irradiation using $\mathrm{ZnO}$ and 'Graft to' $\mathrm{ZnO}$ surfaces with $1 \mathrm{mg}$ to $6 \mathrm{mg}$, and from this plot we observed there is no significant variation in photocatalytic efficiency with $\mathrm{ZnO}$ and 'Graft to' $\mathrm{ZnO}$ films presumably because, in both cases the $\mathrm{ZnO}$ amount was too high causing the prevention of charge transfer.. Consequently, we prepared the films with $\mathrm{ZnO}$ dosage of $0.2 \mathrm{mg}$, $0.4 \mathrm{mg}, 0.6 \mathrm{mg}, 0.8 \mathrm{mg}, 1.0 \mathrm{mg}$, and $1.2 \mathrm{mg}$ and performed the photocatalytic experiment with the same experimental condition under sunlight. As observed from figure 12(B), we can see that the catalytic efficiency was slightly different in both catalysts, from 0.6 $\mathrm{mg}$ to $1.2 \mathrm{mg}$. But in case of film surfaces with $0.2 \mathrm{mg}$ and $0.4 \mathrm{mg}$ of $\mathrm{ZnO}$ dosage, the large variation in catalytic efficiency was observed.
Further, we again reduced the $\mathrm{ZnO}$ dosages on polymerfunctionalized surfaces to optimize the catalytic efficiency. For that we prepared $\mathrm{ZnO}$ and 'Graft to' $\mathrm{ZnO}$ films with $0.05 \mathrm{mg}, 0.1 \mathrm{mg}$, $0.15 \mathrm{mg}, 0.20 \mathrm{mg}, 0.25 \mathrm{mg}$, and $0.3 \mathrm{mg}$ of $\mathrm{ZnO}$ nanoparticles by drop casting method. As depicted in Figure 12(C) we observed the large variation between $\mathrm{ZnO}$ and 'Graft to' $\mathrm{ZnO}$ film catalyst with $0.15 \mathrm{mg}$ to $0.25 \mathrm{mg}$ of $\mathrm{ZnO}$ in dye degradation. It can be attributed to the change in crystallinity while processing the films.
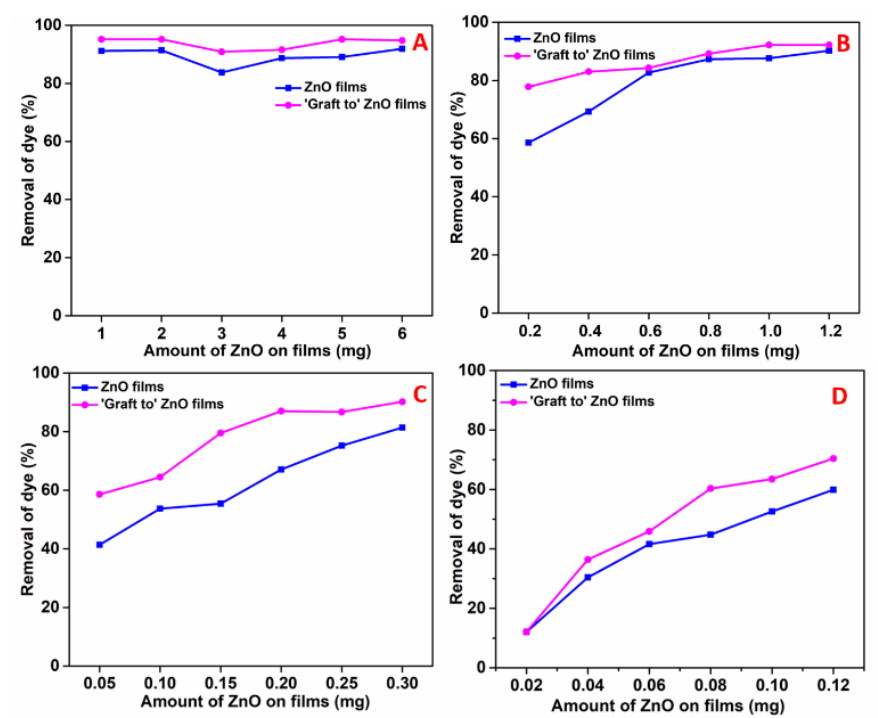

Figure 12. photocatalytic dye degradation using $\mathrm{ZnO}$ films ( $\mathrm{ZnO}$-coated on unfunctionalized surface) and "Graft to" $\mathrm{ZnO}$ film [ZnO-coated on polymerfunctionalized (graft to method) surface] with varying amount of $\mathrm{ZnO}$ : (A) 1 $\mathrm{mg}, 2 \mathrm{mg}, 3 \mathrm{mg}, 4 \mathrm{mg}, 5 \mathrm{mg}$, and $6 \mathrm{mg}$; (B) $0.2 \mathrm{mg}, 0.4 \mathrm{mg}, 0.6 \mathrm{mg}, 0.8 \mathrm{mg}$, $1.0 \mathrm{mg}$ and $1.2 \mathrm{mg}$; (C) $0.05 \mathrm{mg}, 0.1 \mathrm{mg}, 0.15 \mathrm{mg}, 0.2 \mathrm{mg}, 0.25 \mathrm{mg}$ and 0.3 mg; (D) $0.02 \mathrm{mg}, 0.04 \mathrm{mg}, 0.06 \mathrm{mg}, 0.08 \mathrm{mg}, 0.1 \mathrm{mg}, 0.12 \mathrm{mg}$

\section{EXPERIMENTAL PART}

\subsection{Raw materials and solvents}

Thiophene-2- carbonitrile, dimethyl succinate, 1-bromododecane, $\mathrm{N}$ bromosuccinimide (NBS), palladium diacetate, ethynyltrimethylsilane, triphenyl phosphine, copper iodide, aniline, hydroquinone, paraformaldehyde, sodium azide, copper sulphate penta hydrate, Rhodamine B (RhB) dye, dichloromethane, anhydrous THF and anhydrous dimethylformamide (DMF), 2methyl-2-butanol, were purchased from Aldrich chemical company. silica gel (100-200 mesh), sodiun nitrite, anhydrous sodium sulphate, zinc acetate dihydrate, potassium carbonate $\left(\mathrm{K}_{2} \mathrm{CO}_{3}\right)$ sodium hydroxide, potassium tert-butoxide, hydrochloric acid, hydrobromic acid, acetic acid, petroleum ether, hexane, chloroform, ethanol and methanol were purchased from Merk India chemical company and used without any further purification. Azidobenzene (compound S7) was synthesized from aniline by following previous literature report ${ }^{48}$. Distilled water was used in all the cases.

\subsection{Synthesis of monomers:}

The Diketopyrrolopyrrole based dialkynated DADPP monomer (M1) was synthesized using slight modification of method reported in literature and detailed experimental procedure was provided in ESI (as per the reaction scheme S1).In brief, first, (3,6-di(thiophen2-yl)pyrrolo[3,4-c]pyrrole-1,4(2H,5H)-dione) wassynthesized from 2-thiophene carbonitrile ${ }^{36}$. Then (3,6-bis(5-bromothiophen-2-yl)-2,5- 
didodecylpyrrolo[3,4-c]pyrrole-1,4(2H,5H)-dione) was reacted with ethynyltrimethylsilane under Sonogashira coupling reaction condition and deprotected with $\mathrm{K}_{2} \mathrm{CO}_{3} /$ methanol to obtain monomer M1 (2,5-didodecyl-3,6-bis(5-ethynylthiophen-2-yl)pyrrolo[3,4c]pyrrole-1,4(2H,5H)-dione $)^{37}$. The diazide AMDDB monomer (1,4bis(azidomethyl)-2,5-bis(dodecyloxy)benzene) (M2) was synthesised from quinol, by slightly modified literature procedure ${ }^{38}$ as shown in ESI reaction scheme $\mathrm{S} 2$.

\subsubsection{Model click reaction on DADPP molecule (M1 in scheme} 1): Synthesis of 2,5-didodecyl-3,6-bis(5-(1-phenyl-1H-1,2,3triazol-4-yl)thiophen-2-yl)pyrrolo[3,4-c]pyrrole-1,4(2H,5H)dione (compound 1):

compound M1 (70 mg, $0.102 \mathrm{mmol}$ ), azidobenzene (36 mg, 0.306 $\mathrm{mmol})$, copper(II)sulphate pentahydrate $\left(\mathrm{CuSO}_{4} .5 \mathrm{H}_{2} \mathrm{O}\right)(1.2 \mathrm{mg}$, $0.005 \mathrm{mmol})$, and sodium(L)ascarbate $(2.0 \mathrm{mg}, 0.010 \mathrm{mmol})$ were taken in a $25 \mathrm{ml}$ two-neck round bottomed flask and added a mixture of solvents ( $5 \mathrm{~mL}$ of water and $5 \mathrm{~mL}$ of ethanol) under $\mathrm{N}_{2}$ atm. The reaction mixture was heated upto $50^{\circ} \mathrm{C}$ for 22 hours under $\mathrm{N}_{2}$ atm. Then the reaction mass was quenched with saturated ammonium chloride solution and extracted with $100 \mathrm{~mL}$ of chloroform (two times). Then chloroform layer was separated, passed through anhydrous sodium sulphate. Solvent was removed by a rotary evaporator. The crude solid was purified by coloumn chromatography using $50 \%$ chloroform in hexane. Finally, we obtained a purple red color solid $(70 \mathrm{mg}, 75 \%)^{39} .{ }^{1} \mathrm{H} \mathrm{NMR}\left(\mathrm{CDCl}_{3}\right.$, $400 \mathrm{MHz}$ ) Chemical shiftin ppm: 9.05 (d, 2H, Ar-H (thiophene) $\mathrm{J}=4.1 \mathrm{~Hz}), 8.24(\mathrm{~s}, 2 \mathrm{H}$, triazole ring $\mathrm{C}-\mathrm{H}), 7.79(\mathrm{~d}, 2 \mathrm{H} \mathrm{Ar}-\mathrm{H}$ (thiophene) $\mathrm{J}=8.0 \mathrm{~Hz}$ ) 7.77 (t, 4H, Ar-H (phenyl)), 7.57-7.50 (m, 6H, Ar-H (phenyl)), 4.15 (t, 4H, N-C型 2$), 1.78$ (m, 4H, N-CH2- $\left.\underline{\mathrm{H}}_{2}\right)$, $1.46\left(\mathrm{~m}, 4 \mathrm{H}, \mathrm{N}-\mathrm{CH}_{2}-\mathrm{CH}_{2}-\mathrm{CH}_{2}\right), 1.36-1.22\left(\mathrm{~m}, 32 \mathrm{H}, \mathrm{n}-\mathrm{CH}_{2}\right)$, and 0.86 (t, $\left.6 \mathrm{H}, \mathrm{CH}_{2}-\underline{\mathrm{C}}_{3}\right)$ ppm. ${ }^{13} \mathrm{C} \mathrm{NMR}\left(\mathrm{CDCl}_{3}, 100.64 \mathrm{MHz}\right)$ Chemical shift in ppm: 161.32, 142.55, 139.53, 137.82, 136.37, $129.92,129.33,129.21,125.63,118.01,109.62,108.27,76.71$, $42.38,37.9,31.92,30.15,29.71,29.63,29.51,29.56,29.36,26.96$, 22.69, and $14.1 \mathrm{ppm}$. FT-IR (KBr) Stretching frequency: 3305, $3050,2920,2850,2140$, and $1663 \mathrm{~cm}^{-1}$.

\subsection{Click polymerization}

\subsubsection{Synthesis of click polymerP1:}

In a clean and dry $25 \mathrm{~mL}$ two neck round bottom flask under nitrogen atmosphere,the compound M1 $(0.292 \mathrm{mmol})$ and M2 (0.292 mmol) was dissolved in anhydrous tetrahydrofuran. The reaction mixture was again degassed with $\mathrm{N}_{2}$ gas. Then $5 \mathrm{~mol} \%$ of $\mathrm{CuI}$ and $0.2 \mathrm{~mL}$ distilled diisopropyl amine was dissolved into the small vial and degassed with $\mathrm{N}_{2}$ gas. After 5 mins this solution becomes a yellowish green color. This solution was charged into the reaction mass in one portion. Then heating was started and the reaction condition was maintained at $50^{\circ} \mathrm{C}$ for 72 hours. After 72 hours violet color reaction mass was obtained. The solvent was removed using vacuum and charged $100 \mathrm{~mL}$ of chloroform. The chloroform layer was washed with saturated ammonium chloride and water two times. Finally,the organic layer was separated and distilled out the solvent. The solid was reprecipitated with chloroformmethanol mixture. The click polymer P1was purified by soxhlet extraction using methanol, acetone, diethylether and chloroform sequentially. Pure polymers were obtained from the chloroform layer. ${ }^{1} \mathrm{H} \mathrm{NMR}\left(\mathrm{CDCl}_{3}, 400 \mathrm{MHz}\right.$, ) Chemical shift in ppm: 9.048.81 (broad, 2H, Ar-H (thiophene)), 7.77-7.68 (broad, 1H, triazoleH), 7.40-7.25 (broad, 2H, Ar-H (thiophene)), 6.85-6.70 (broad, 2H, Ar-H (phenyl)), 5.58-5.40 (broad, 4H, benzyl-H), 4.10-3.75 (broad, $\left.8 \mathrm{H}, \mathrm{N}-\underline{\mathrm{H}}_{2}\right), 1.82-0.60$ (n- $\mathrm{CH}_{2}$ and $\mathrm{CH}_{3}$ group of alkyl chains) ppm. FT-IR (KBr) Stretching frequency: 3070, 2938 and $1657 \mathrm{~cm}^{-1}$.GPC; Mn value of $\mathrm{P} 1$ is 7435 .

\subsubsection{Synthesis of click polymer P2 :}

We took a cleaned and dry $25 \mathrm{~mL}$ two neck round bottom flask, monomers M1 (0.292 mmol) and M2 (0.292 mmol), were taken, and added $5 \mathrm{~mol} \%$ of $\mathrm{Cu}(\mathrm{II}) \mathrm{S}_{4} .5 \mathrm{H}_{2} \mathrm{O}$, Na-ascarbate ( $5 \mathrm{~mol} \%$ ), distilled diisopropylamine $(0.2 \mathrm{~mL})$, and anhydrous tetrahydrofuran $(5 \mathrm{~mL})$. Again, the reaction mixture was degassed with $\mathrm{N}_{2}$ gas. The reaction mixture was heated at $50^{\circ} \mathrm{C}$ and maintained the reaction condition for 48 hours in the $\mathrm{N}_{2}$ atmosphere. Visual changes of the reaction mass color from red to violet-red, along with indication of viscosity increase was also observed. After completion of the reaction solvent was removed under vacuum and charged $100 \mathrm{~mL}$ of chloroform into reaction mixture followed by washing with saturated ammonium chloride solution and water two times. The organic layer was separated out and passed through the anhydrous sodium sulphate. Solvent was distilled out and the crude solid was purified by reprecipitation with chloroform- methanol mixture. The polymers P2 was further purified by soxhlet extraction method sequentially by different solvents (methanol, acetone, diethyl ether, and finally chloroform). Finally, pure polymer P2 was obtained from the chloroform fraction. ${ }^{1} \mathrm{H}$ NMR $\left(\mathrm{CDCl}_{3}, 400 \mathrm{MHz}\right)$ Chemical shift values in ppm: $8.97(2 \mathrm{H}, \mathrm{Ar}-\mathrm{H}$ (thiophene) $), 7.82(1 \mathrm{H}$, triazole ring $\mathrm{C}-\mathrm{H}), 7.41(2 \mathrm{H}, \mathrm{Ar}-\mathrm{H}$ (thiophene)), $6.90(2 \mathrm{H}, \mathrm{Ar}-\mathrm{H}$ (phenyl)), 5.54 (4H, benzyl-H) 4.23-4.10 (4H, N-C $\left.\underline{\mathrm{H}}_{2}\right), 4.05-3.91\left(4 \mathrm{H}, \mathrm{O}-\mathrm{CH}_{2}\right)$, 1.75-0.69 $\left(\mathrm{CH}_{2}\right.$ and $\mathrm{CH}_{3}$ groups in aliphatic chains) ppm. FT-IR (KBr) Stretching frequency: 3080, 2920 and $1650 \mathrm{~cm}^{-1}$. GPC; Mn value for P2 polymer is 5967 .

3.4. Functionalization of surfaces with click polymers (Graft To approach) on self assembled monolayer (SAM) of azide:

In a $100 \mathrm{~mL}$ single neck flask, under $\mathrm{N}_{2}$ atmosphere, azidefunctionalized glass surfaces ( 5 number ), $5 \mathrm{mg}$ of click polymer (P2) and $7.5 \mathrm{~mL}$ of anhydrous tetrahydrofuran were taken. Then 1 $\mathrm{mg}$ of CuI, $0.02 \mathrm{~mL}$ distilled diisopropyl amine and $2.5 \mathrm{~mL}$ of anhydrous DMF was added into the small vial and degassed with $\mathrm{N}_{2}$ gas. After 5 mins this solution becomes a yellowish green color. This solution was charged into the reaction mass in one portion and heated for 2 hours under reflex condition. Then it was cooled to room temperature and ultrasonicated by 10 mins. Finally polymer functionalized glass surfaces were washed several time with tetrahydrofuran and dried at $50^{\circ} \mathrm{C}$ under vacuum for 2 hours. These polymer-functionalized glass surfaces were stored in desiccators ${ }^{45}$.

\subsection{Preparation of drop-casted surfaces with polymer}

We dissolved $1 \mathrm{mg}$ of click polymer (P2) in $10 \mathrm{~mL}$ of chloroform to prepare a polymer stock solution (100 ppm concentration). Then $20 \mu \mathrm{L}$ of polymer solution were dropcasted on glass slides (square slides $2.5 \mathrm{~cm} \times 2.5 \mathrm{~cm}$ ) at $50^{\circ} \mathrm{C}$. The resulting drop-casted polymer surfaces (it containing $2 \mu \mathrm{g}$ of click polymer) 
were dried at $50^{\circ} \mathrm{C}$ for 6 hours and it was used for further surface characterization studies as a control sample.

\subsection{Preparation of $\mathrm{P} 2-\mathrm{ZnO}$ composite}

The polymer-ZnOcomposite $(\mathrm{P} 2-\mathrm{ZnO})$ was prepared by using a previously reported procedure. Initially, we prepared a $\mathrm{ZnO}$ dispersed solution (495 $\mathrm{mg}$ of $\mathrm{ZnO}$ in $100 \mathrm{~mL}$ of methanol) with half an hour sonication. Meanwhile we prepared the click polymer solution by dissolving $5 \mathrm{mg}$ polymer in $5 \mathrm{~mL}$ of chloroform. Then the polymer solution was added dropwise into $\mathrm{ZnO}$ dispersed solution and the mixture was maintained under stirring condition for 1 hour at ambient temperature. Then the solvents were removed by rotovapour. Finally we got $\mathrm{P} 2-\mathrm{ZnO}$ composite material $4855 \mathrm{mg}$, purple color solid) after drying at $110^{\circ} \mathrm{C}$ for 12 hours. These composite materials were used for photocatalytic experiments directly ${ }^{47}$.

3.7. Preparation of unfunctionalized surfaces coated with $\mathrm{ZnO}$ and unfunctionalized surfaces coated with $\mathrm{P} 2-\mathrm{ZnO}$ composite

We prepared the $\mathrm{ZnO}$-coated surfaces with different amounts of $\mathrm{ZnO}$ nanoparticles by drop casting on glass surfaces for control experiments. Initially we took $5 \mathrm{mg}$ of $\mathrm{ZnO}$ nanoparticles in vial and made a dispersed solution with $2.5 \mathrm{~mL}$ of ethanol. Then the dispersed $\mathrm{ZnO}$ solution was dropcasted on glass surfaces at $90^{\circ} \mathrm{C}$. The $\mathrm{ZnO}$ film was dried at $110^{\circ} \mathrm{C}$ for 12 hours before being used in a photocatalytic experiment. For preparing the $\mathrm{P} 2-\mathrm{ZnO}$-coated surface, we measured $5 \mathrm{mg}$ of $\mathrm{P} 2-\mathrm{ZnO}$ composite and made the dispersed solution in $2.5 \mathrm{~mL}$ of ethanol. Then the dispersed $\mathrm{P} 2-\mathrm{ZnO}$ solution was dropcasted on glass slides. The resulting P2-ZnO film was dried at $110^{\circ} \mathrm{C}$ for 12 hours before use.

3.8.Preparation of $\mathrm{ZnO}$ films (ZnO-coated on unfunctionalized surface) and "Graft to" $\mathrm{ZnO}$ films [ZnO-coated on polymerfunctionalized (graft to method) surface]

We prepared $\mathrm{ZnO}$ films and 'Graft to' $\mathrm{ZnO}$ films with different amounts of $\mathrm{ZnO}$ nanoparticles on 'Graft to' surfaces [polymerfunctionalized surfaces] by dropcastiog method. For that we prepared two set of $\mathrm{ZnO}$ dispersed solution with different weights like (i) 0.02 $\mathrm{mg}, 0.04 \mathrm{mg}, 0.06 \mathrm{mg}, 0.08 \mathrm{mg}, 0.1 \mathrm{mg}, 0.12 \mathrm{mg}$, (ii) $0.05 \mathrm{mg}, 0.1$ $\mathrm{mg}, 0.15 \mathrm{mg}, 0.2 \mathrm{mg}, 0.25 \mathrm{mg}, 0.3 \mathrm{mg}$, (iii) $0.2 \mathrm{mg}, 0.4 \mathrm{mg}, 0.6 \mathrm{mg}$,

\section{Author Information (Email address)}

*DebasisSamanta: debasis@clri.res.in

Phone: +91-44 24437189. Fax:+91-44-24911589;

PeriyamuthuRamar : ppramar93@gmail.com

\section{Orcid ID}

*DebasisSamanta: 0000-0002-3043-8033

Periyamuthu Ramar: 0000-0002-2786-9502

Notes:The authors declare no competing financial interest.

\section{References:}

(1) Chen, X.; Xu, X.; Li, W.; Sun, B.; Yan, J.; Chen, C.; Liu, J.; Qian, J.; Sun, D. Effective Drug Carrier Based on Polyethylenimine-Functionalized Bacterial Cellulose with
$0.8 \mathrm{mg}, 1.0 \mathrm{mg}, 1.2 \mathrm{mg}$, (iv) $1 \mathrm{mg}, 2 \mathrm{mg}, 3 \mathrm{mg}, 4 \mathrm{mg}, 5 \mathrm{mg}$, and 6 $\mathrm{mg}$. Then the dispersed solutions were drop casted on glass surfaces and polymer-functionalized surfaces at $90^{\circ} \mathrm{C}$ to get the $\mathrm{ZnO}$ and 'Graft to' $\mathrm{ZnO}$ films respectively. Finally the films were dried at $110^{\circ} \mathrm{C}$ for 12 hours.

\section{CONCLUSIONS}

Diketopyrrolopyrrole-based triazole-linked "click" polymers were synthesized successfully using two different copper-based catalysts. Computational models and theoretical calculations predicted localized HOMO, LUMO and moderate band gaps between the energy levels. Further, self-assembled monolayer (SAM) formation followed by "graft to" method of immobilization was used successfully to immobilize those polymers to surfaces. Spectroscopic and GPC techniques provided the information about the effect of two different catalysts on the degree of polymerization. Fluorescence microscopy, Atomic force microscopy (AFM), scanning electron microscopy and other analysis confirmed a more dense and regular surface coverage when SAM formation followed by graft to techniques were used rather than conventional drop casting technique. Finally, the surfaces as prepared by SAM formation followed by Graft To techniques have been used as efficient sensitizers for the photocatalytic process of dye degradation.

\section{ACKNOWLEDGEMENTS}

Financial support from DST project (ECR/2015/000219) and CSIR-CLRI In house project MLP13 is gratefully acknowledged. CSIR-CLRI communication Number is 1610 .

\section{Electronic Supporting Information}

Detailedexperimental procedures for synthesis of monomers and surfaces functionalization and its ${ }^{1} \mathrm{H}$ and ${ }^{13} \mathrm{C}$ NMR spectra, Characterization of zno based photocatalysts and the detailed experimental procedure of photocatalytic dye degradation $\begin{array}{llll}\text { processwere } & \text { available } & \text { in }\end{array}$

Controllable Release Properties. ACS Appl. Bio Mater. 2018, 1, 42-50. 
(2) Ye, S.; Jiang, L.; Wu, J.; Su, C.; Huang, C.; Liu, X.; Shao, W. Flexible Amoxicillin-Grafted Bacterial Cellulose Sponges for Wound Dressing: In Vitro and in Vivo Evaluation. ACS Appl. Mater. Interfaces 2018, 10, 5862-5870.

(3) Rouabhia, M.; Asselin, J.; Tazi, N.; Messaddeq, Y.; Levinson, D.; Zhang, Z. Production of Biocompatible and Antimicrobial Bacterial Cellulose Polymers Functionalized by RGDC Grafting Groups and Gentamicin. ACS Appl. Mater. Interfaces 2014, 6, 1439-1446.

(4) Vy, N. C. H.; Liyanage, C. D.; Williams, R. M. L.; Fang, J. M.; Kerns, P. M.; Schniepp, H. C.; Adamson, D. H. SurfaceInitiated Passing-through Zwitterionic Polymer Brushes for SaltSelective and Antifouling Materials. Macromolecules 2020, 53, 10278-10288.

(5) Stratakis, E.; Mateescu, A.; Barberoglou, M.; Vamvakaki, M.; Fotakis, C.; Anastasiadis, S. H. From superhydrophobicity and water repellency to superhydrophilicity: smart polymerfunctionalized surfaces. Chem. Commun. 2010, 46, 4136-4138.

(6) Liu, X.; Ye, Q.; Song, X.; Zhu, Y.; Cao, X.; Liang, Y.; Zhou, F. Responsive wetting transition on superhydrophobic surfaces with sparsely grafted polymer brushes. Soft Matter 2011, 7, 515-523.

(7) Sun, W.; Zhou, S.; You, B.; Wu, L. Polymer BrushFunctionalized Surfaces with Reversible, Precisely Controllable Two-Way Responsive Wettability. Macromolecules 2013, 46, 7018-7026.

(8) Lv, Y.; Cao, Y.; Svec, F.; Tan, T. Porous polymer-based monolithic layers enabling $\mathrm{pH}$ triggered switching between superhydrophobic and superhydrophilic properties. Chem. Commun. 2014, 50, 13809-13812.

(9) Dunderdale, G. J.; England, M. W.; Urata, C.; Hozumi, A. Polymer Brush Surfaces Showing Superhydrophobicity and AirBubble Repellency in a Variety of Organic Liquids. ACS Appl. Mater. Interfaces 2015, 7, 12220-12229.

(10) Dubner, M.; Spencer, N. D.; Padeste, C. Light-Responsive Polymer Surfaces via Postpolymerization Modification of Grafted Polymer-Brush Structures. Langmuir 2014, 30, 1497114981.

(11) Huang, P.-C.; Shen, M.-Y.; Yu, H.-h.; Wei, S.-C.; Luo, S.C. Surface Engineering of Phenylboronic Acid-Functionalized Poly(3,4-ethylenedioxythiophene) for Fast Responsive and Sensitive Glucose Monitoring. ACS Appl. Bio Mater. 2018, 1, 160-167.

(12) Yang, X.; Shen, B.; Jiang, Y.; Zhao, Z.; Wang, C.; Ma, C.; Yang, B.; Lin, Q. A novel fluorescent polymer brushes film as a device for ultrasensitive detection of TNT. J. Mater. Chem. A 2013, 1, 1201-1206.

(13) Niu, Q.; Gao, K.; Lin, Z.; Wu, W. Surface molecularimprinting engineering of novel cellulose nanofibril/conjugated polymer film sensors towards highly selective recognition and responsiveness of nitroaromatic vapors. Chem. Commun. 2013, 49, 9137-9139.

(14) Welch, M. E.; Ritzert, N. L.; Chen, H.; Smith, N. L.; Tague, M. E.; Xu, Y.; Baird, B. A.; Abrua, H. D.; Ober, C. K. Generalized Platform for Antibody Detection using the Antibody Catalyzed Water Oxidation Pathway. J. Am. Chem. Soc. 2014, 136, 1879-1883.

(15) Wang, A.-Q.; Cui, Y.-Z.; Tao, F.-R.; Wang, D.-h.; Li, T.D.; Xu, J.-K. Preparation of a functionalized glass sensor and its sensing performances for nitroaromatics. Thin Solid Films 2016, 598, 299-304.

(16) Page, Z. A.; Narupai, B.; Pester, C. W.; Bou Zerdan, R.; Sokolov, A.; Laitar, D. S.; Mukhopadhyay, S.; Sprague, S.; McGrath, A. J.; Kramer, J. W.; Trefonas, P.; Hawker, C. J. Novel Strategy for Photopatterning Emissive Polymer Brushes for Organic Light Emitting Diode Applications. ACS Cent. Sci. 2017 3, 654-661.
(17) Lee, S.; Jang, M.; Yang, H. Optimized Grafting Density of End-Functionalized Polymers to Polar Dielectric Surfaces for Solution-Processed Organic Field-Effect Transistors. ACS Appl. Mater. Interfaces 2014, 6, 20444-20451.

(18) Kang, H.; Hong, S.; Lee, J.; Lee, K. Electrostatically SelfAssembled Nonconjugated Polyelectrolytes as an Ideal Interfacial Layer for Inverted Polymer Solar Cells. Adv. Mater. 2012, 24, 3005-3009.

(19) Yang, L.; Sontag, S. K.; LaJoie, T. W.; Li, W.; Huddleston, N. E.; Locklin, J.; You, W. Surface-Initiated Poly(3methylthiophene) as a Hole-Transport Layer for Polymer Solar Cells with High Performance. ACS Appl. Mater. Interfaces 2012, 4, 5069-5073.

(20) Panzarasa, G.; Soliveri, G.; Sparnacci, K.; Ardizzone, S. Patterning of polymer brushes made easy using titanium dioxide: direct and remote photocatalytic lithography. Chem. Commun. 2015, 51, 7313-7316.

(21) Samanta, D.; Sarkar, A. Immobilization of biomacromolecules on self-assembled monolayers: methods and sensor applications. Chem. Soc. Rev. 2011, 40, 2567-2592.

(22) Murugan, P.; Krishnamurthy, M.; Jaisankar, S. N.; Samanta, D.; Mandal, A. B. Controlled decoration of the surface with macromolecules: polymerization on a self-assembled monolayer (SAM). Chem. Soc. Rev. 2015, 44, 3212-3243.

(23) Chiu, J.-M.; Tai, Y. Improving the Efficiency of ZnOBased Organic Solar Cell by Self-Assembled Monolayer Assisted Modulation on the Properties of $\mathrm{ZnO}$ Acceptor Layer. ACS Appl. Mater. Interfaces 2013, 5, 6946-6950.

(24) Samanta, D.; Murugan, P.; Ananthakrishnan, S. J.; Somanathan, N.; Das, S. K.; Jaisankar, S. N.; Mandal, A. B. "Click" polymerization on a self-assembled monolayer: a convenient approach to functionalize various surfaces with polytriazoles. Chem. Commun. 2012, 48, 12068-12070.

(25) Qin, A.; Lam, J. W. Y.; Tang, B. Z. Click polymerization. Chem. Soc. Rev. 2010, 39, 2522-2544.

(26) Qin, A.; Lam, J. W. Y.; Tang, B. Z. Click Polymerization: Progresses, Challenges, and Opportunities. Macromolecules 2010, 43, 8693-8702.

(27) Anwer, H.; Mahmood, A.; Lee, J.; Kim, K.-H.; Park, J.-W.; Yip, A. C. K. Photocatalysts for degradation of dyes in industrial effluents: Opportunities and challenges. Nano Res. 2019, 12, 955972.

(28) Olaru, N.; Calin, G.; Olaru, L. Zinc Oxide Nanocrystals Grown on Cellulose Acetate Butyrate Nanofiber Mats and Their Potential Photocatalytic Activity for Dye Degradation. Ind. Eng. Chem. Res. 2014, 53, 17968-17975.

(29) Yan, B.; Wang, Y.; Jiang, X.; Liu, K.; Guo, L. Flexible Photocatalytic Composite Film of ZnO-Microrods/Polypyrrole. ACS Appl. Mater. Interfaces 2017, 9, 29113-29119.

(30) Wang, Y.; Zheng, Y.-Z.; Lu, S.; Tao, X.; Che, Y.; Chen, J.F. Visible-Light-Responsive TiO2-Coated ZnO:I Nanorod Array Films with Enhanced Photoelectrochemical and Photocatalytic Performance. ACS Appl. Mater. Interfaces 2015, 7, 6093-6101.

(31) Alzahrani, E. Chitosan Membrane Embedded With $\mathrm{ZnO} / \mathrm{CuO}$ Nanocomposites for the Photodegradation of Fast Green Dye Under Artificial and Solar Irradiation. Analytical chemistry insights 2018, 13 AN - 29593375, 1177390118763361.

(32) Mohd Hir, Z. A.; Abdullah, A. H.; Zainal, Z.; Lim, H. N. Photoactive Hybrid Film Photocatalyst of Polyethersulfone-ZnO for the Degradation of Methyl Orange Dye: Kinetic Study and Operational Parameters. Catalysts 2017, 1-13.

(33) Martins, P. M.; Gomez, V.; Lopes, A. C.; Tavares, C. J.; Botelho, G.; Irusta, S.; Lanceros-Mendez, S. Improving Photocatalytic Performance and Recyclability by Development of Er-Doped and Er/Pr-Codoped TiO2/Poly(vinylidene 
difluoride)/Trifluoroethylene Composite Membranes. J. Phys. Chem. C 2014, 118, 27944-27953.

(34) Sardar S, K. P., Remita H, Liu B, Lemmens P, Kumar Pal S, Ghosh S. Enhanced Charge Separation and FRET at Heterojunctions between Semiconductor Nanoparticles and Conducting Polymer Nanofibers for Efficient Solar Light Harvesting. Sci Rep. 2015, 5, DOI: 10.1038/srep17313.

(35) Gupta, A.; Saurav, J. R.; Bhattacharya, S. Solar light based degradation of organic pollutants using $\mathrm{ZnO}$ nanobrushes for water filtration. RSC Adv. 2015, 5, 71472-71481.

(36) Huo, L.; Hou, J.; Chen, H.-Y.; Zhang, S.; Jiang, Y.; Chen, T. L.; Yang, Y. Bandgap and Molecular Level Control of the Low-Bandgap Polymers Based on 3,6-Dithiophen-2-yl-2,5dihydropyrrolo[3,4-c]pyrrole-1,4-dione toward Highly Efficient Polymer Solar Cells. Macromolecules 2009, 42, 6564-6571.

(37) Braunecker, W. A.; Oosterhout, S. D.; Owczarczyk, Z. R.; Larsen, R. E.; Larson, B. W.; Ginley, D. S.; Boltalina, O. V.; Strauss, S. H.; Kopidakis, N.; Olson, D. C. Ethynylene-Linked Donor:Acceptor Alternating Copolymers. Macromolecules 2013, 46, 3367-3375.

(38) Sampath, S.; Boopathi, A. A.; Mandal, A. B. "Bottom-up" self-assembly and "cold crystallization" of butterfly shaped tetrabenzofluorene molecules. Phys. Chem. Chem. Phys. 2016, 18, 21251-21258.

(39) Punzi, A.; Maiorano, E.; Nicoletta, F.; Blasi, D.; Ardizzone, A.; Ventosa, N.; Ratera, I.; Veciana, J.; Farinola, G. M. 1,2,3-Triazole-Diketopyrrolopyrrole Derivatives with Tunable Solubility and Intermolecular Interactions. Eur. J. Org. Chem. 2016, 2016, 2617-2627.

(40) Karim, M. A.; Cho, Y.-R.; Park, J. S.; Kim, S. C.; Kim, H J.; Lee, J. W.; Gal, Y.-S.; Jin, S.-H. Novel fluorene-based functional "click polymers" for quasi-solid-state dye-sensitized solar cells. Chem. Commun. 2008, 16, 1929-1931.

(41) Murugan, P.; Raghavendra, V.; Chithiravel, S.; Krishnamoorthy, K.; Mandal, A. B.; Subramanian, V.; Samanta, D. Experimental and Theoretical Investigations of Different Diketopyrrolopyrrole-Based Polymers. ACS Omega 2018, 3, 11710-11717.

(42) Kim, D. H.; Song, H. J.; Lee, E. J.; Ko, E. J.; Moon, D. K. Low band gap polymer consisting of quinacridone and diketopyrrolopyrrole and isoindigo units: correlation of ordered structure and intramolecular charge transfer properties. Synthetic Metals 2015, 210, 304-313.

(43) Karim, M. A.; Cho, Y.-R.; Park, J. S.; Ryu, T. I.; Lee, M. J.; Song, M.; Jin, S.-H.; Lee, J. W.; Gal, Y.-S. Comparison of Three Different Click Reaction Methods for the Synthesis of Fluorene-Based Polymers and Performance in Quasi-Solid-State DSSCs. Macromol. Chem. Phys. 2008, 209, 1967-1975.

(44) Ponnappa, S., Arumugam, S., Manzhos, S., MacLeod, J., Spratt, H., O'Mullane, A., \& Sonar, P. Investigation of thiophene flanked diketopyrrolopyrrole monomers with straight and branched alkyl chains and their electropolymerization study. $J$. Mater. Res. 2017, 32, 2707-2718.

(45) Paoprasert, P.; Spalenka, J. W.; Peterson, D. L.; Ruther, R. E.; Hamers, R. J.; Evans, P. G.; Gopalan, P. Grafting of poly(3hexylthiophene) brushes on oxides using click chemistry. $J$. Mater. Chem. 2010, 20, 2651-2658.

(46) Xi, Y.; Wolf, C. M.; Pozzo, L. D. Self-assembly of donoracceptor conjugated polymers induced by miscible "poor" solvents. Soft Matter 2019, 15, 1799-1812.

(47) Murugan, P.; Ramar, P.; Mandal, A. B.; Samanta, D. Investigating the Photocatalytic Performances of Nanocomposites Containing Narrow-band-gap Copolymers and ZnO. ChemistrySelect 2019, 4, 14214-14221.

(48) Conte, G.; Cristiano, R.; Ely, F.; Gallardo, H. New 1,4Diaryl [1,2,3]-Triazole Liquid Crystals Using a Click Reaction. Synthetic Communications 2006, 36, 951-958. 